\title{
Product Data Technology (PDT) Impact on Life Cycle Assessment (LCA); the case of CASCADE and DEPUIS
}

\author{
Anna Moreno (Corresponding author) \\ UTT- Unit- ENEA- Italian National Agency for New Technologies \\ Energy and Sustainable Economic Development \\ Via Anguillarese 301, 00123 S. Maria di Galeria, Italy \\ Tel: 39-063-048-6474Ｅ-mail: Anna.moreno@enea.it
}

Anna Amato

UTT- Unit- ENEA- Italian National Agency for New Technologies

Energy and Sustainable Economic Development

Via Anguillarese 301, 00123 S. Maria di Galeria, Italy

Tel: 39-063-048-6474Ｅ-mail: Anna.amato@enea.it

\begin{abstract}
Musadaq Hanandi
Department of Management engineering - University of Rome "Tor Vergata"

Via del Politecnico, 1 - 00133 Rome, Italy
\end{abstract}

Tel: 39-063-048-6474Ｅ-mail: Musadaq.hanandi@uniroma2.it

Received: July 16, 2012 Accepted: September 16, 2012

doi:10.5296/emsd.v1i2.2092 URL: http://dx.doi.org/10.5296/emsd.v1i2.2092

\begin{abstract}
This paper presents the cases of CASCADE (Co-operation and Standards for life Cycle Assessment Data in Europe) and DEPUIS (Design Environmental friendly Product Using information Standards), two projects that aimed at improving the eco-design of new products and services through an innovative implementation of ISO information standards. The paper
\end{abstract}


presents an overview of the projects' objectives and results, thru highlighting the best practices for software manufacturers, consultants, suppliers, and customers, in improving Product Data Technology (PDT) integration during the implementation process of different manufacturing software's and applications inside their firms.

Keywords: Product Data Technology, ISO 10303, STEP, ISO 14000, Life Cycle Assessment

\section{Introduction}

In the last decades, Information technology (IT) played a great role in shaping the modern manufacturing industry. Many software and IT application packages are currently used in every major manufacturing enterprise, with engineers and researchers working in front of their computers rather than using pens and paper. In simple words, information technology became the backbone of the manufacturing sector. The ICT integration in the manufacturing industry, lead to create new opportunities and motivates the enterprises to improve their competitiveness in the market through enhanced collaborative work and interoperability between the different computer systems and applications used in different firms.

As a result of this change in approach, the organizations' products, data and information are becoming the principal factors of success in today's knowledge-based economy; what an organization knows is becoming more important than what an organization owns.

Thus, enterprises pay greater attention to their products' data and information standardization: they aim at creating their unique language to collaborate with partners and suppliers using different software and applications in areas such as cost minimization, life cycle assessment, production and supply chain performance.

However, many researchers highlighted the difficulty of exchanging business information and data with partners and enterprises due to incompatibility problems among the various information representation structures used by different computers systems and applications in different industry networks (Ray and Jones, 2006; Panetto and Molina, 2008). The problem of exchanging data and product information in electronic format as desirable is considered a real barrier to partnership innovation and development as well as causing inefficiencies and an increase in costs (Jardim-Gonçalves et al., 2006; Panetto et al., 2006; Brunnermeier and Martin, 1999).

The answer to these obstacles was found by creating common exchange models for each set of engineering data that needs to be exchanged. These models are collectively known as products data technology (PDT), which enables the industrial sector to exchange data and information based on international standards.

Today, standardization is implemented in many manufacture sectors, thru different industrial systems and related applications, starting from the blueprint design phase, production and commercialization, and ending with assessing the product's environmental impact (life cycle assessment) (Jardim-Goncalves et al., 2006). Standardization is growing rapidly and is becoming an apparent necessity for data and information exchange in different manufacturing sectors. 


\section{Macrothink}

These standards were developed by the TC184/SC4, a technical committee of the International Organization for Standards (ISO); they enable the computerized representation of information for products, processes, and their properties independently from computer system or software applications, using a generic information model and comprehensive solutions that satisfy particular industrial requirements for data modeling during the product's life cycle (Kramer and $\mathrm{Xu}, 2009$ ). This paper introduces the cases of CASCADE (Co-operation and Standards for life Cycle Assessment Data in Europe) and DEPUIS (Design environmentally friendly Products Using Information Standards), two projects aimed at improving the eco-design of new products and services through an innovative implementation of ISO information standards.

The paper introduces an overview of the objectives and results of the projects, as well as recommendations based on best practices for software manufacturers, consultants, suppliers and customers on how to improve PDT integration during the implementation process of different manufacturing software's and applications inside their firms.

In Section 2 the paper introduces product data technology; section 3 explains the life cycle assessment; section 4 highlights the PDT's impact on the life cycle assessment; Section 5 of the paper presents the case of two European Commission funded projects, CASCADE and DEPUIS, both aiming at supporting the firms in integrating the PDT to their products' life cycle. Section 6 concludes the paper with further recommendations.

\section{Product Data Technology}

Every software system is unique in its internal organization of data, and also in how data items are identified and labeled (software data model). Direct transfer of data from a software system to a different one will fail because the receiving system tries to interpret the transferred data according to its own internal data model, which is different from the source one (Swindells 2008).

For instance, the string of symbols AISI $304 \mathrm{~L}$ can be interpreted by engineers to mean a stainless steel with a particular proportion of additives to iron, and it will still have the same meaning if written in the following ways: AISI_304_L, AISI/304L, AISI-304-L. A computer, however, would interpret these initials as different products and would be unable to read and process the attached value in the correct way. Indeed, materials are much more complex than just initials and a property value. Digital misinterpretation due to different measurement units could cause serious problems in the real, tangible world.

The conversion from one type of software to another to achieve the correct interpretation of data may be possible, but it is not the best solution. Data produced by one software system requires the conversion from a data model to another one, if it is to be used on a different platform.

For direct communication among $\mathrm{n}$ different data models, $\mathrm{n}(\mathrm{n}-1)$ separate data conversion interfaces are required, if each software system is to be able to interpret any of the different data models it could receive (see figure 1). 

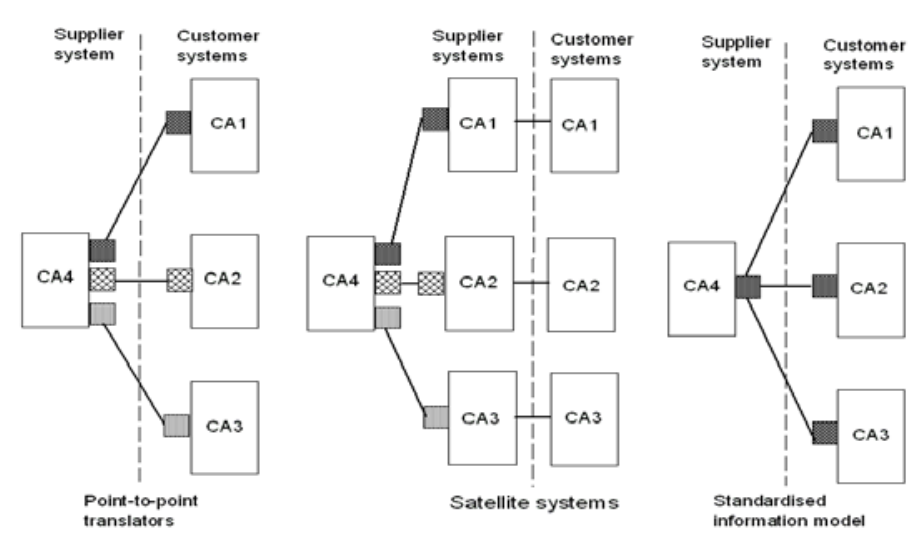

Figure 1. A comparison of three strategies for the exchange of digital information

Today, standard specifications for computer representation of technical information have become possible as a result of the development of PDT. These international product data standards provide a neutral mechanism to describe product data throughout the product's life cycle, regardless of the software system used. Thanks to the particular nature of this description, which is suitable for neutral file exchange between dissimilar computer systems, product databases and long-term archiving can also be implemented and shared. This use of PDT standards as specifications to manage information flows in the life cycle of a product is called information engineering (Swindells 2000). Therefore, the product data standards offer a basis for quality control and quality assurance and thus ensure their validity and reliability.

The application of PDT standards within the products whole-life (cradle to grave) approach is particularly important for end-of-life scenarios (Swindells and Moreno 2007; Swindells, 2008). During most of a product's lifetime it is advisable to keep all the given values.

The lifetime of most products, particularly of complex products, is longer than the lifetime of the computer systems that were used to design them and control their production. At the end of the life of a product, the data describing the product needs to be processed in unknown systems and in unknown locations.

It is clear that this information and data should accompany the product throughout its lifetime, and the information/data requires a standardized specification ensuring that it can still be processed whenever and wherever needed. A specification for information is an "information model" a formal description - of types of ideas, facts, and processes that together form a model of a portion of the real world and that provide an explicit set of rules for the interpretation of the description. If an information model is written in a computer-sensible language, such as EXPRESS (Wilson 1998), it has the additional quality of being computer-processable. A computer-processable dictionary defines the terms that identify the data items. To communicate information avoiding misunderstandings, everyone in the communication chain must use the same information model and the same dictionary.

\section{Life Cycle Assessment}

Life Cycle Assessment, in the first part of the term (life cycle) refers to the notion that a fair, 
holistic assessment needs to take into account raw material production, manufacture, distribution, use and disposal including all intervening transportation steps necessary or caused by the product's existence. The sum of all those steps - or phases - is the life cycle of the product. The life-cycle of a product is often a long and complicated process. It covers several areas and phases involving designers, the assembly chain, marketing people, retailers and consumers. The term "Life Cycle Assessment" (LCA), as defined by ISO 10404, is a method to assess the impact of the products' manufacturing processes on the environment from "cradle to grave", i.e. from the extraction of the raw materials for use in production to their disposal at the end of their useful life including all intervening transportation steps necessary or caused by the product's existence (ISO 1998). Moreover, a full LCA includes all resource depletion, emissions and impacts of pollutants released into the external environment (water, air, and soil) during the phases of production, consuming, and disposal.

LCA is increasingly being used at the design stage of new products, where the need for changes can be more easily identified and the cost of making those changes is minimum. Both retrospective assessment and LCA at the design stage need access to data and this will usually need to be collected from different sources and used in combination with a computer system. However, different sources will have developed their data systems using different software and platforms and each data system will therefore have a different internal representation for the data it contains. The result is that data from different sources cannot be combined and used efficiently without a great deal of uncertainty, extra work and additional costs. The potential benefits of being able to use a combination of LCA data systems in the EU are therefore difficult to be achieved.

In the field of LCA the agreement on the format of data has been published as the international standard ISO 14048 (ISO, 2002). The LCA is a method for assessing the environmental impact of a product throughout its life-cycle stages; it requires a comprehensive database of resource and emissions data for a wide range of processes for such an assessment to be achieved.

On the other hand, all the data are generated electronically by the users, with hardly any use of standards. The most important issues are therefore related to accessibility, comparability and quality assurance of data used in the LCA of products and the integration of LCA in the design process.

According to SETAC (1993) these products' environmental impact, is generally categorized according to how the products affect ecosystems, human health, environment and natural resources. The LCA provides a set of objective data useful to assess environmental effects of product use and the extent to which each aspect of the intended product (i.e. Book, Cruise ship, etc.) contributes to its environmental impact.

\section{The PDT role in LCA}

Many researchers agreed on the PDT as a tool for enhancing the organization's performance, especially in the environmental innovation area, and as an important contributor to products' Eco-Design success, since it facilitates many of the PDT and collaborative-based activities. 


\section{Macrothink}

However, it is important to underline that PDT is more than just a helping hand tool; the PDT provides a comprehensive solution for all the products' environmental life cycle problems i.e. different LCA systems, different Data Base systems, and different data formats.

The rapid exchange of product data through the use of trustworthy and stable standards for PDT could help to bridge the gap between research and development and the marketplace for eco-design products, technologies, services, processes, and management methods. One of the critical barriers still hampering the development of the green industry is the difficulty in comparing products from the environmental point of view. Such a comparison can be drawn using the LCA, but a reliable LCA requires the collection of real data exchange throughout the life cycle of the product, from the cradle to the grave.

However, the majority of LCAs are made with existing statistical data based on average figures deriving from old researches. A valid comparison of products requires actual and up-to-date figures referring to those particular products, processes, or services, and to the particular inputs into these products, processes, or services.

This part of the paper illustrates how PDT standards can support the enterprise in bridging off the gaps with their LCA processes by presenting some of the standards that could be used to collect, exchange, and archive these data. Normally all the following phases of a product's life cycle, produce data that need to be collected from different enterprises using different systems and platforms:

- The supply of raw materials, the other resources needed to extract the raw materials, and transport.

- The manufacturing of components that will be part of the final product - anything from a book to a cruise ship.

- The information about all the inputs and outputs of the production needs to be known.

- The distribution and retail phase, which includes packaging and transport. Both depend on the location of producer and customer.

- The use phase, which requires energy (renewable or not) and may produce pollution.

- The use phase may include the maintenance of the product necessary to extend its life.

- The recycling phase, which includes separating the product into different recyclable materials or, in the best case, reconditioning and reusing entire assemblies.

- The disposal phase of any materials that are not recycled but can no longer be used.

Figure 2 shows some of the standards that could be used to collect information relevant to these stages in the life cycle so that information can be transferred from one stage to another and used to improve the design from an environmental point of view. 


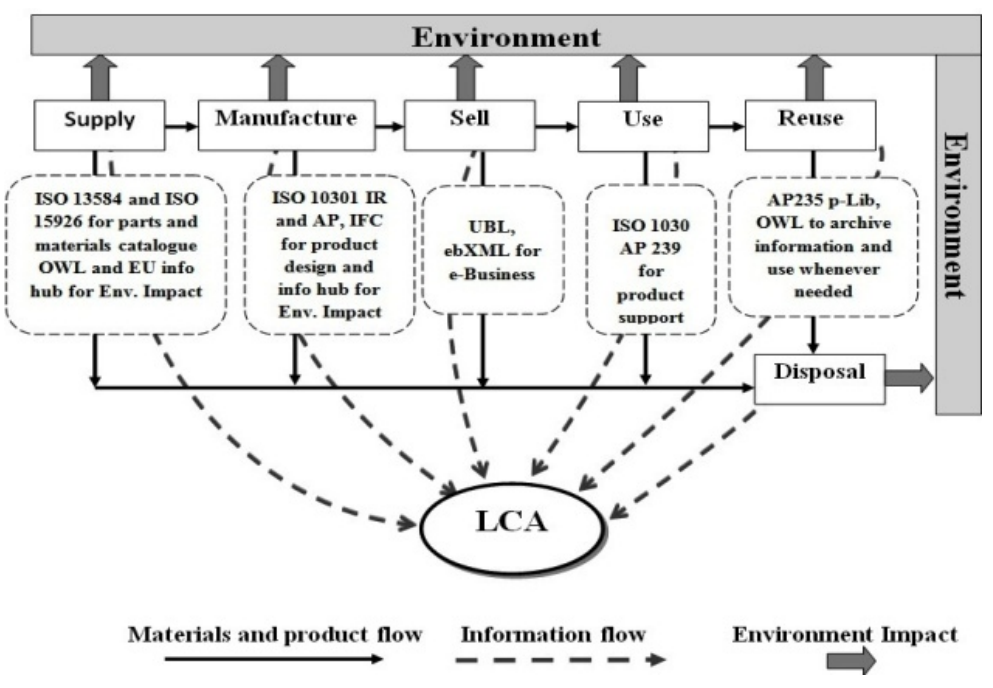

Figure 2. Products LCA model

\section{Case Screening}

In this section the paper illustrates the case of two projects, CASCADE and DEPUIS, both funded by the European Commission to promote the use of PDT in current manufacturing processes and product life cycles. The projects made use of distance learning as a training and development tool to promote the PDT among Europe's industrial members.

\subsection{The CASCADE Project}

The CASCADE project is a real demonstration case in the area of co-operation and standards for LCA data in Europe. The project's main objectives were to achieve accessibility, comparability and quality assurance for data used in the LCA of products, as well as the integration of LCA in the design process. Additionally, the project offers e-learning packages to enhance learners' knowledge and expand their understanding of the importance of the LCA and PDT. The project's structured network was composed of 13 members from 7 different European countries, involved in different working areas from research, industry, LCA software developers and data base providers, LCA analysts and IT experts.

The project was supported by European Commission for duration of 36 months starting from the 1st of January 2002. In this paper the project's general objectives and results will be presented excluding the details, although more information for researchers and practitioners is available on the CASCADE project's website: www.pdt.enea.it.

\subsubsection{The Project Aims}

The CASCADE project's objectives can be summarized into two main goals as follows:

Firstly, to include environmental data in the design process, by defining common procedures for development of database content and by means of collaborative work between research organizations and other partners, as well as through the definition of methods of access to the database based upon existing international standards; Secondly, to facilitate data exchange and independence from any given system through the definition of a database 
structure (based upon existing international standards) and to provide initial content for the database, in alignment with education materials for the performance of life cycle assessment.

\subsubsection{The Project Model}

The CASCADE model has been conceived to create a free flow of data and information created in LCA software based PDT standards, and to make it transferable via the internet and available online as engineering database hubs, as well as through the systems of customers' enterprises. See Figure 3.

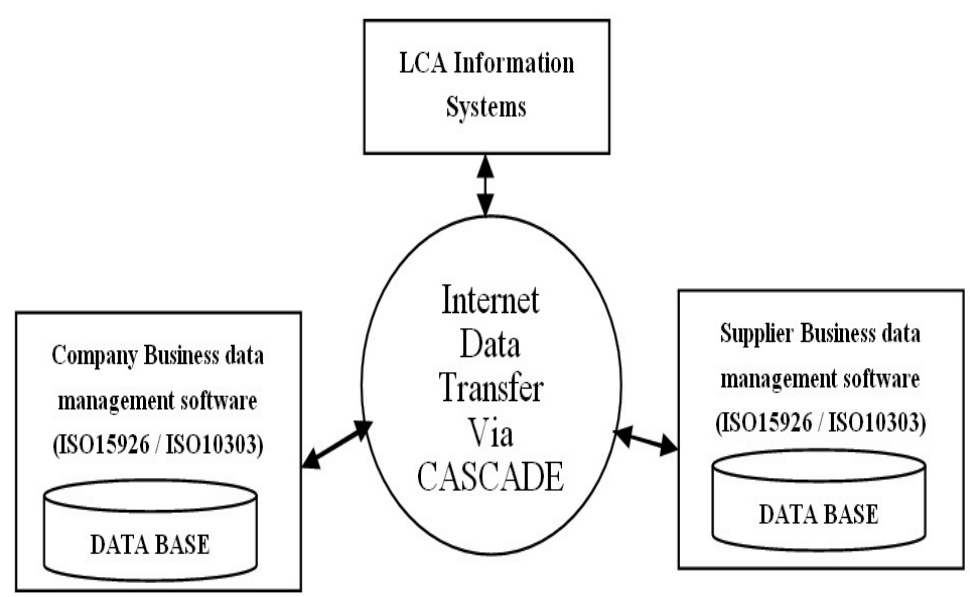

Figure 3. The CASCADE project model

To achieve these objectives, the project adopts standards for the representation of LCA data, as described in ISO 14048. In addition, a common method for specifying LCA data in databases for product designers and practitioners has been defined in LCA working area.

However, these methods are based on the Code of Practice of the Materials database Demonstrator Programme developed by the European Commission in the early 90's and bring together existing standards, particularly ISO 10303, ISO 13584 and ISO 15531 for computer - readable data and ISO 14048 for the presentation of LCA data in document format. The purpose of these methods is to allow the transfer and exchange of data in different formats using standards based on (ISO 14048), which is a standard terminology records the LCA data, without using computer interpretable standard format for LCA data.

The project develops a standard format by deriving a formal ontology from ISO 14048. This ontology is represented using OWL (Web Ontology Language) and can be used directly to create a standard XML format for LCA data.

The ontology has also been related to the basic engineering concepts, as its defined in ISO 15926-2 'Life cycle data for process plant'. This enables LCA data to be held in an ISO 15926-2 data warehouse alongside other engineering design, construction and operations data. See the project's website for more information (www.pdt.enea.it). 


\subsubsection{The Project Outputs}

The project's outputs and results can be summarized in the following points:

- The project supports the firms operating in different manufacturing sectors in the mutual exchange of data through the use of guides and manuals via the CASCADE website.

- In addition, the project supports suppliers using different software tools with a database in a standard ISO 14048-based format, and allows suppliers in a chain to produce LCAs and provide them via the internet regardless of the different enterprises' software and formats. See Figure 4.

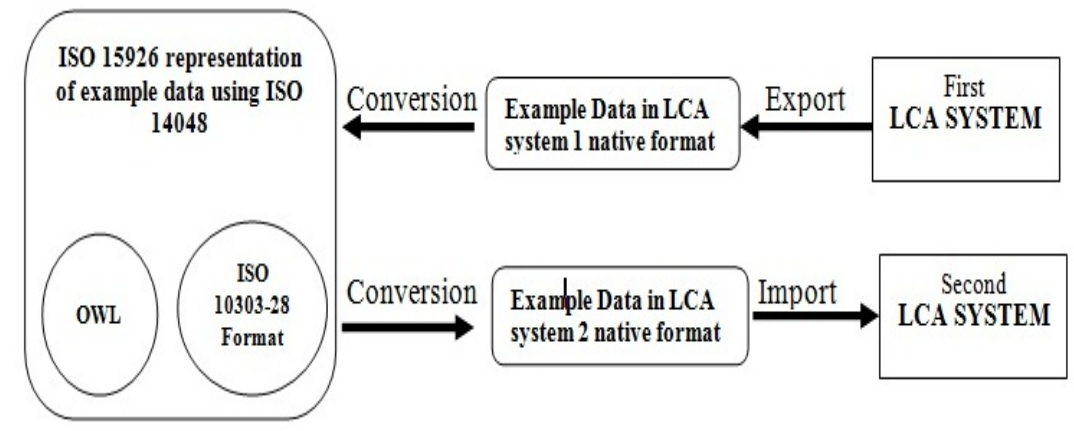

Figure 4. Data transfers between different LCA systems

- The project supports data transfer between business systems and applications inside the enterprise. The rules used to create the ontology are the same as those used to allow the transfer of engineering data between business information systems like Enterprise Resource Planning (ERP) tools, product data management tools, building management systems and purchasing databases. Thus, the project paves the way for information already existing within companies to be extracted and used for life cycle assessment. This innovation has the potential to considerably reduce the time taken to create in-house studies. See Figure 4.

- The project presents a path for future commercial sensitivities, if there are commercial issues about the data; the LCA can be constructed via the web by an independent third party service provider, protecting the source data whilst still providing the necessary details to customers. This can also overcome the lack of expertise in SMEs by customers, who can rely on experts. See Figure 4.

The project's basic databases can allow the upgrade of 'generic' databases. If web-based databases of products available across a particular industry segment are made available - even anonymously - across the internet, this allows the creation of generic data. The project has great potential for the IT industry, in the early stages of design.

\subsection{The DEPUIS Project}

The DEPUIS project (Design of Environmental-friendly Product Using Information Standards) was the natural follow up to the CASCADE project because of the difficulty encountered by the LCA community to make use of the complexities of PDT standards. The project was set up with 9 partners coming from 7 European countries. The project was funded by the Enterprise and Industry Directorate-General (DG). 
The partners were mainly from the standardization PDT world together with two partners from the LCA community and one from the professional certification system. The project lasted for 24 months starting from 2006. In addition, the DEPUIS project was recognized by the DG Enterprise as one of the best innovation tools.

\subsubsection{The Project Aims}

DEPUIS aims at improving the environmentally friendly design of new products and services through an innovative use of information standards.

The standards are applications of ISO 10303 (product data representation and exchange), ISO 13584 Parts Libraries and ISO 15926 Reference data library. Each of these standards uses an information model to provide a computer-processable specification for product data that is independent from any proprietary software system.

These standards support the neutral exchange of data between different computer systems and are the basis for long-term data retention and archiving. The main strategic objective of the project was to enable more companies, particularly SMEs, to use Life Cycle Thinking (LCT) on the environmental impact of their design of new products, in conformity with the Communication on Integrated Product Policy of the European Commission.

\subsubsection{The Model}

The project entailed the development of e-learning courses (multimedia book model) to promote a better understanding of new technologies and opportunities created by using the information standards and ISO 14048; the model also includes workshops and training courses to achieve interaction between users and developers of the standards to speed up the dissemination of new methods. The project's model targeted software developers and engineers, environmental advisers and consultants.

The project attempts to:

- Increase the awareness of the benefits of life cycle thinking (LCT) in the design of new products and processes;

- Create understanding of the importance of standard specifications to achieve comparability in communication and in the archiving of technical data to support life-cycle thinking at the design stage;

- Provide feedback to standards developers about the perceived benefits of this new technology;

- Provide basic knowledge to software developers in order to produce better software compliant with international standards.

\subsubsection{Results}

The outcome can be viewed on the website www.if-sc4.enea.it, where all the results of the DEPUIS project were made available (ISO TC Sc4 community and forum on the official web site). Many people take advantage of the content in the "multimedia handbook", an online 
version of the DEPUIS handbook in the project. The multimedia handbook contains:

- The description of the content of the main PDT and ISO 14000 series standards;

- The access to e-learning courses and video lessons explaining the standards;

- Access to a database of technical documents useful for better understanding those standards;

- Information about software useful for the implementation of the PDT standards.

\section{Conclusion}

The LCA and PDT are becoming more and more important for the modern industry. Many enterprises and factories start with implementing the PDT in their products' life cycle for better quality, less cost and more efficient production processes. CASCADE and DEPUIS present great supporting tools by providing general information, e-learning packages and data transfer systems for engineers, companies, consultants, factories, etc.

Despite the project still needing the support of software manufacturers to implement the PDT's capability, LCA consultants will find the PDT technology useful. Furthermore, customers need to decide what information they need, how accurate it needs to be, and what it should be used for, while the industry needs to look at the products and supply chains.

\section{References}

Amato, A., Moreno. A., \& Swindells. N. (2008). The DEPUIS project: Design of environmentally friendly products using information standards. In C. Gaetano (Eds.), Computer-Aided Innovation (CAI),IFIP International Federation for Information Processing (pp. 135-145). Boston. Springer.

Brunnermeier, S. B., \& Martin, S. A. (2002). Interoperability costs in the US automotive supply chain, Supply Chain Management: An International Journal, 7(2), 71-82, http://dx.doi.org/10.1108/13598540210425821

The CASCADE Project Official website from the Italian National Agency for New Technologies, Energy and Sustainable Economic Development (ENEA) Web site at http://www.pdt.enea.it/

The Commission of the European Communities, COM. (2003). Integrated Product Policy. Building on Environmental Life-Cycle Thinking, Communication from the Commission to the Council and the European Parliament, 302 Brussels, 18 June. Online: http://ec.europa.eu/environment/ipp/pdf/eesopinions.txt

The Commission of the European Communities, COM. (2004). Stimulating Technologies for Sustainable Development: an Environmental Technologies Action Plan for the European Union, Communication from the Commission to the Council and the European Parliament 38, Brussels, 28 January. Online: http://www.ieep.eu/assets/216/environmentaltechnologies.pdf

Design of Environmental-friendly Products Using Information Standards from the Italian 
National Agency for New Technologies, Energy and Sustainable Economic Development (ENEA) Web site http://www.depuis.enea.it and http://www.sc4-if.enea.it

Filstad. C. (2011). Organizational commitment through organizational socialization tactics. Journal of Workplace Learning, 376-390, http://dx.doi.org/10.1108/13665621111154395

Integrated Product Policy (IPP) - Environment - European Platform on Life Cycle Assessment (LCA), more information available on the European Commission Website http://ec.europa.eu/environment/ipp/lca.htm

ISO/TC184/SC4. (1994). ISO 10303-1: Industrial automation systems and integration product data representation and exchange-Overview and fundamental principles, International Standard of Organization (ISO), Geneva, Switzerland.

ISO 14040. (2006). Environmental management - Life cycle assessment - Principles and framework (ISO14040:2006). International Standard of Organization (ISO), Geneva, Switzerland.

ISO 14044. (2006). Environmental management - Life cycle assessment - Requirements and guidelines (ISO14044:2006). International Standard of Organization (ISO), Geneva, Switzerland.

Jardim-Goncalves, R., Figay, N., \& Steiger, A. (2006). Enabling interoperability of STEP Application Protocols at meta-data and knowledge level. International Journal of Technology Management, 36(4), 402-421.

Kramer, T., \& Xu, X. (2009). STEP in a Nutshell. In: XU, X. \& NEE, A. Y. C. (eds.) Advanced Design and Manufacturing Based on STEP. London. Springer. http://dx.doi.org/10.1007/978-1-84882-739-4_1

Panetto, H., \& Molina A. (2008). Enterprise Integration and Interoperability in Manufacturing Systems: trends and issues. H. Panetto and A. Molina (Eds). Special issue on Enterprise Integration and Interoperability in Manufacturing Systems, Computers In Industry, 59 (7) 641- 646, September, Elsevier, http://dx.doi.org/10.1016/j.compind.2007.12.010

Panetto, H., Jardim-Gonçalves, R., \& Pereira, C. (2006). EManufacturing and Web-Based Technology for Intelligent Manufacturing and Networked Enterprise. Journal of Intelligent Manufacturing, 17(6), 639-640. http://dx.doi.org/10.1007/s10845-006-0033-1

Ray, S. R., \& Jones, A. T. (2006). Manufacturing interoperability. Journal of Intelligent Manufacturing, 17(6), 681-688. http://dx.doi.org/10.1007/s10845-006-0037-x

Swindells, N. (2002). Communicating materials information: Product data technology for materials. International Materials Reviews 47(1), 31-45. http://dx.doi.org/10.1179/095066001225001058

Swindells, N. (2008). The transfer of knowledge and innovation in waste reduction. House of lord Paper, 163(II), 315-335. London: Stationery Office Limited. 


\section{Macrothink}

Environmental Management and Sustainable Development ISSN 2164-7682 2012, Vol. 1, No. 2

Swindells, N., \& Moreno, A. (2007). Standards to support a sustainable world: A response from ISO TC184/SC4 to the Communiqu'e to ISO Committees on sustainability. International Standard Organization, Geneva, Switzerland.

\section{Copyright Disclaimer}

Copyright reserved by the author(s).

This article is an open-access article distributed under the terms and conditions of the Creative Commons Attribution license (http://creativecommons.org/licenses/by/3.0/). 